\title{
Voltaire pensador da tolerância: do combate ao fanatismo à luta contra 0 ateísmo
}

\author{
Sébastien Charles \\ Sebastien.Charles@USherbrooke.ca \\ Université de Sherbrooke, Sherbrooke, Canadá
}

resumo A militância de Voltaire em favor da tolerância parece um truísmo, dado o conhecimento do caráter sistemático de sua luta contra o fanatismo religioso e a reabilitação dos condenados que essa mesma luta logrou. Mas é forçoso reconhecer que, em seu combate contra o fanatismo, Voltaire parece mais interessado pelos efeitos produzidos no nível prático do combate, e notadamente pelo sucesso obtido em favor dos defendidos, muitas vezes póstumo, infelizmente, que pela preocupação de convencer teoricamente seus adversários. A prova está no fato de que o Tratado sobre a tolerância tem apenas uma pequena parte argumentativa, o essencial reside em mostrar por meio de exemplos os estragos do fanatismo, particularmente o religioso, durante o curso da história. Contudo, Voltaire não é alheio a uma verdadeira reflexão teórica sobre o conceito de tolerância, mas esta the parece ineficaz ou incapaz de conquistar a conviçç̃o da maioria de seus contemporâneos que prefere a denúncia das injustiças apresentada em termos de fatos mais do que em termos de direito. Resta que Voltaire não se restringe à exposição dos fatos, ele sabe que a filosofia e o direito têm sua palavra sobre 0 assunto, e que a teoria influi sobre a prática como esta sobre a primeira. Daí porque, parece-me, a reflexão de Voltaire sobre a noção de tolerância não permanece somente no nível das tomadas de posição do filósofo de Ferney a respeito deste ou daquele sujeito cujos direitos foram agredidos, mas que ela deve também ser apreendida no nível teórico, pois, sobre este ponto também, a posição de Voltaire é ao mesmo tempo original e sem concessão, rompendo radicalmente com aquela de um de seus mestres ingleses, John Locke.

palavras-chave Voltaire; religião; tolerância; teoria; prática

Recebido em 02 de junho de 2012. Aceito em 01 de agosto de 2012.

Traduzido por Rodrigo Brandão

doispontos, Curitiba, São Carlos, vol. 9, n. 3, p.29-44, dezembro, 2012 
A militância de Voltaire em favor da tolerância parece um truísmo, dado o conhecimento do caráter sistemático de sua luta contra o fanatismo religioso e a reabilitação dos condenados que essa mesma luta logrou. Mas é forçoso reconhecer que, em seu combate contra o fanatismo, Voltaire parece mais interessado pelos efeitos produzidos no nível prático do combate, e notadamente pelo sucesso obtido em favor dos defendidos, muitas vezes póstumo, infelizmente, que pela preocupação de convencer teoricamente seus adversários. A prova está no fato de que o Tratado sobre a tolerância tem apenas uma pequena parte argumentativa, o essencial reside em mostrar por meio de exemplos os estragos do fanatismo, particularmente o religioso, durante o curso da história. Contudo, Voltaire não é alheio a uma verdadeira reflexão teórica sobre o conceito de tolerância, mas esta lhe parece ineficaz ou incapaz de conquistar a convicção da maioria de seus contemporâneos que prefere a denúncia das injustiças apresentada em termos de fatos mais do que em termos de direito. Resta que Voltaire não se restringe à exposição dos fatos, ele sabe que a filosofia e o direito têm sua palavra sobre o assunto, e que a teoria influi sobre a prática como esta sobre a primeira. Daí porque, parece-me, a reflexão de Voltaire sobre a noção de tolerância não permanece somente no nível das tomadas de posição do filósofo de Ferney a respeito deste ou daquele sujeito cujos direitos foram agredidos, mas que ela deve também ser apreendida no nível teórico, pois, sobre este ponto também, a posição de Voltaire é ao mesmo tempo original e sem concessão, rompendo radicalmente com aquela de um de seus mestres ingleses, John Locke.

\section{De Pascal a Voltaire: a questão da tolerância religiosa}

A tolerância na idade clássica recobre toda uma série de questões diferentes que se referem ao mesmo tempo a problemáticas religiosas e políticas, como aquelas sobre a relação entre ortodoxia e liberdade de pensar (a verdade deve ser imposta ou é possível tolerar o exercício de uma busca livre em matéria religiosa?), a relação entre religião nacional e os súditos políticos (é preciso constranger e perseguir os indivíduos que não aderem ao culto oficial ou devemos tolerar sua presença?), mas igualmente ela faz repensar o estatuto da consciência (podemos modificar o conteúdo 
da crença pelo constrangimento sem conduzir a comportamentos hipócritas?). No que concerne ao domínio propriamente religioso, digamos que a questão principal é aquela da relação entre consciência individual e verdade religiosa. Face ao paradigma defendido pelos partidários da intolerância, que tomam como dever absoluto a defesa da verdade e não se embaraçam nem um pouco com o uso do constrangimento, que lhes aparecia totalmente legítimo, os pensadores da tolerância evocavam em coro o direito da consciência individual de buscar sinceramente a verdade e a não se contentar com os dogmas oficiais, e legitimavam por isso a tese da consciência errante (LECLER, 1994). Já evocada por Abelardo em Scito te ipsum, essa tese da consciência errante foi defendida de três maneiras diferentes pelos pensadores da tolerância da idade clássica.

A primeira é talvez a mais difícil de sustentar, é a posição daqueles que pensam que mesmo a consciência podendo errar, não deixa de existir uma verdade religiosa que é reconhecível ainda que não provada ou demonstrada - ou ao menos que seria reconhecível se todos os crentes tivessem boa fé. De acordo com essa perspectiva, ao invés de opor sinceridade subjetiva e verdade objetiva, é preciso admitir graus entre a heresia religiosa e a verdade dogmática e reconhecer um estatuto particular ao verdadeiro. Mais do que considerar a verdade como oposto exato do erro, é possível pensá-la como uma síntese de tudo que há de partidário e parcial nas posições consideradas heréticas. Assim, o erro não é concebido como um defeito que se deve eliminar, mas como uma obliquidade que deve ser corrigida, e que possui um valor próprio que pode ser utilizado e reconhecido. É no fundo a posição defendida, cada um a sua maneira, por Pascal e Leibniz, o primeiro em seu domínio religioso, o segundo no domínio metafísico.

Para ser breve, focarei apenas o caso de Pascal. Como todos os pensadores da tolerância, ele se pronuncia contra o uso do constrangimento em matéria de fé:" A conduta de Deus, que dispõe todas as coisas com doçura, é de pôr a religião no espírito por razões, e no coração pela graça. Mas querer colocá-la no espírito e no coração pela força e por ameaças, não é pôr a religião, mas o terror, terrorem potis quam religionem". (PASCAL, 1963, p. 523). Essa recusa do constrangimento, no entanto, não conduz Pascal a rejeitar a ideia de que pode haver um critério objetivo da verdade religiosa. Ao contrário, existe, segundo ele, uma verdade religiosa, que corresponde 
a uma religião particular, a religião cristã, e mais particularmente, a religião católica vista sob o ângulo do agostianismo estrito, com sua insistência na dualidade da natureza no homem, religião cuja verdade pode ser verificada tanto pela razão quanto pelo coração. E é em relação a esta verdade religiosa específica que Pascal apresenta as heresias como verdades parciais e partidárias que podem ser distribuídas de ambos os lados da ortodoxia católica.Visto que a verdade é dupla (sendo a natureza humana dupla), é normal existir visões de partido dela, posições heréticas que correspondem a perspectivas truncadas, que tem em conta apenas um aspecto da coisa, e que devem ser corrigidas para serem integradas ao ponto de vista superior. É possível então tolerar o erro, ainda mais porque ele nunca é totalmente falso, e buscar a despeito de tudo corrigi-lo pela tomada do ponto de vista ideal, o que corresponde à preocupação apologética de Pascal.

A segunda maneira de tratar a questão é adotada por aqueles que pensam também que a verdade religiosa existe, mas consideram que ela não pode ser conhecida, que ela é essencialmente escondida, descoberta apenas de maneira parcial e mutilada, o que faz com que não possamos alcançá-la. Essa posição reúne tanto aqueles segundo os quais todas as religiões são parcialmente verdadeiras, desde que reconheçam seu caráter parcial e o fato de que se relacionam todas à transcendência de uma verdade pura que permanece escondida, quanto aqueles que buscam estabelecer um credo mínimo, um mínimo comum ao conjunto das posições religiosas porquanto todas concordam em algo comum.

Entre os defensores da primeira posição, que pensam que a tolerância deve ser defendida em nome do reconhecimento da particularidade das religiões, encontra-se o Bodin do Colloquium heptaplomeres, manuscrito que termina com a ideia de que todas as religiões são boas, todas manifestam a glória de Deus, e que é preciso, portanto, tolera-las (BODIN, 1984). Essa posição será retomada por Lessing na famosa cena do conto dos três anéis de Nathan le Sage, em que reencontraremos uma mensagem idêntica: todo indivíduo pode viver livremente sua religião, desde que todas as religiões particulares reconheçam o caráter parcial da verdade que as ilumina, e que cada uma aceite possuir apenas uma parte da verdade (LESSING, 2006, p. 7).

Os defensores da segunda posição pensam que a constituição de um credo mínimo permitiria superar as divisões e os afrontamentos dos 
particularismos religiosos. Eles apelam à religião natural que postula a existência de artigos fundamentais comuns a todas as religiões. Pensemos por exemplo no De veritate e no De religione laïi de Herbert de Cherbury, onde são propostos cinco artigos fundamentais da religião natural: (1) há um Deus; (2) Deus deve ser servido, (3) o verdadeiro culto é o culto da piedade, (4) é necessário se arrepender dos pecados; (5) há uma retribuição para nossas ações (CHERBURY, 2002). Alguns visam à constituição de um cristianismo mínimo reduzido ao símbolo dos apóstolos ou ainda a um artigo de fé único (o reconhecimento da divindade de Cristo) que seria o denominador comum das diferentes igrejas cristãs. Erasmo, pregando o retorno a um cristianismo purificado, já considerava esta via, assim como o autor protestante das Ruses de Satan $(1565)^{1}$, que recomendava o retorno ao símbolo dos apóstolos, posição da qual se inspirará Locke em seu Cristianismo razoável.

Enfim, a terceira maneira de responder à questão reúne os pensadores da tolerância que reivindicam o primado da ortopraxia sobre a ortodoxia. Para eles, a vida religiosa e a maneira de se conduzir superam a verdade religiosa. Esta posição supõe que a religião consiste menos em crer nesta ou naquela verdade do que em obedecer àquele que se reconhece como Deus. Ela é comum aos três grandes representantes da tolerância do século XVII: Bayle, Locke e Espinosa. Em seu Comentário filosófico, Bayle mostra que o problema é menos crer no verdadeiro (afinal é impossível estar seguro de se ter a verdade no domínio religioso), do que crer sinceramente. No fundamento da fé se encontra uma boa fé, uma sinceridade, que é a vontade sincera de obedecer a Deus e da qual só Deus é o juiz. Daí a insistência de Bayle sobre a inviolabilidade da consciência, e o retorno ao conceito de consciência errante: não devemos ser punidos se nos enganamos de boa fé.

Há uma ideia próxima em Locke, para quem cada um tem o direito de determinar aquilo que crê necessário à sua salvação - aqui reencontramos o critério da sinceridade. Para Locke, o critério da sinceridade repousa sobre a distinção clara entre a natureza e finalidade da sociedade religiosa, sociedade na qual os homens ingressam para garantir sua salvação, e aquelas da sociedade civil, sociedade na qual os homens ingressam para bem viver juntos e que é de natureza contratual. Assim, a sociedade religiosa é necessariamente plural, pois existem diversas vias conduzindo à salvação, e 
cada um deve poder determinar livremente aquilo que the parece necessário a seu fim e se unir a outros para lá chegar conjuntamente.

A posição de Espinosa não é muito distante daquela de Bayle e de Locke. No Tratado teológico-político, Espinosa mostra que o importante no âmbito religioso são as virtudes de justiça e caridade, para ele os dois objetos essenciais da Escritura. Encontramos mais uma vez o primado da sinceridade e da deferência a um Deus concebido como legislador em detrimento da dimensão da verdade da religião. Desse ponto de vista, o domínio da verdade é heterogêneo ao domínio da obediência, o que permite Espinosa opor a salvação pela razão descrita na Ética à salvação pela obediência apresentada no Tratado teológico-político. Contrariamente a Pascal ou Leibniz, que desejavam pensar juntamente razão e fé, filosofia e teologia, os partidários da ortopraxia separam o domínio do conhecimento, a filosofia, suscetível de chegar ao verdadeiro graças ao exercício da luz natural, do domínio da obediência, a teologia, em que se trata antes de tudo de ser sincero e de se submeter.

A posição geral de Voltaire no interior desse debate sobre a tolerância vai, grosso modo, na mesma direção. Contra Pascal,Voltaire pensa não ser possível determinar objetivamente o valor de uma religião revelada em relação a outra, e ainda menos afirmar que há apenas uma verdadeira (sua crítica dos milagres ou do testemunho humano sobre os quais Pascal funda sua apologética é radical neste ponto). Com Locke, Espinosa ou Bayle, ele reconhece a superioridade da ortopraxia e pensa igualmente que é preciso distinguir radicalmente filosofia e teologia. Mas ele se distancia de Locke, pois ao invés de um cristianismo razoável, ele prefere promover uma religião razoável, cuja definição aproximada ele fornece no artigo "Religião" do Dicionário Filosófico:

Depois de nossa santa religião, sem dúvida a única boa, qual seria a menos má? Não seria a mais simples? Não seria a que ensinasse muita moral e poucos dogmas? A que se empenhasse em tornar os homens justos sem torná-los absurdos? A que não ordenasse a crença em coisas impossíveis, contraditórias, injuriosas para a Divindade e perniciosas para o gênero humano e não se atrevesse a ameaçar com penas eternas qualquer um que tenha um juízo normal? Não seria a que não sustentasse a sua crença com carrascos e não inundasse a terra com sangue por causa de sofismas ininteligíveis? (...) A que 
unicamente ensinasse a adoração de um só Deus, a justiça, a tolerância e a humanidade? (VOLTAIRE, 1968, p. 483-484)

Se se afasta em parte de Locke sobre este ponto, Voltaire se aproxima de Espinosa evocando uma dupla relação no que se refere à salvação, moral, para as almas bem nascidas que não têm necessidade do medo ou da esperança para saber como agir, e religiosa, para as almas fracas que têm necessidade de ameaças e de castigos para bem se conduzir.

Nesse sentido, a moral é a religião dos fortes, e a religião a moral dos fracos. A moral é de inspiração divina e universalmente partilhada, as religiões são particulares e humanas, e é preciso antes de tudo reter delas seu conteúdo ético, que é conforme às regras morais instituídas por Deus e que podemos descobrir graças ao instrumento específico que nos deu para isso, a razão. Mesmo dando frequentemente nascimento a posições sectárias de onde decorrem a superstição e o fanatismo, as religiões não deixam de ser em geral úteis, em grande parte por razões pragmáticas, como lembra o capítulo XX do Tratado sobre a tolerância, em que a preferência de Voltaire é inequívoca no que se refere ao ateísmo:

Tal é a fraqueza do gênero humano e tal é sua perversidade que, para ele, certamente é preferível ser subjugado por todas as superstições possíveis, contanto que não sejam mortíferas, do que viver sem religião.

O homem sempre teve necessidade de um freio e, ainda que fosse ridículo fazer sacrifícios aos faunos, aos silvanos, às náiades, era bem mais útil e razoável adorar essas imagens fantásticas da divindade do que se entregar ao ateísmo. Um ateu argumentador, violento e poderoso seria um flagelo tão funesto quanto um supersticioso sanguinário (...). Onde quer que haja uma sociedade estabelecida, uma religião é necessária: as leis protegem contra os crimes conhecidos, e a religião, contra os crimes secretos (VOLTAIRE, 1968, p. 242).

Apesar de tudo, o ideal seria atingir uma versão purificada, próxima da religião natural dos pensadores da Renascença, da qual seriam banidos os excessos das religiões positivas (superstição, culto de relíquias, crença nos milagres, fanatismo).

É neste ponto que Voltaire se separa de todos esses predecessores em nome de um teísmo hiper-racionalista que exclui do domínio religioso 
não somente o impossível, mas também o absurdo e o incrível - próprios a todas as religiões reveladas -, e que se atém somente ao essencial:"Quase tudo que vai além da adoração de um Ser supremo e da submissão do coração às suas ordens eternas é superstição" (VOLTAIRE, 1968, p. 536). Só pode haver aí fé razoável, e, portanto, o domínio da fé religiosa se encontra inteiramente desqualificado, como lembra uma fórmula lapidar do Dicionário Filosófico que desvela a essência da crença: "a fé consiste em crer naquilo que a razão não crê, o que já é outro milagre” (VOLTAIRE, 1968, p. 232). Seguindo sua reflexão sobre a religião, o Voltaire do Dicionário Filosófico se pergunta sobre qual seria a religião verdadeira, se o cristianismo não existisse. E responde: "aquela na qual não houvesse seitas; aquela na qual todos os espíritos concordassem necessariamente. Ora, em que dogma todos os espíritos estão de acordo? Na adoração de um Deus e na probidade" (VOLTAIRE, 1968, p. 520). Eis o único conteúdo de uma religião que se pretende ao mesmo tempo evidente e universal, e que somente o é porque é racional, pois a afirmação da existência de Deus aparece como muito mais provável que sua negação e o reconhecimento de uma consciência moral supera também uma concepção determinista da atividade humana que negaria toda ideia de responsabilidade moral. E é justamente porque existe um jogo para a liberdade, porque a passagem da desrazão à razão não está definitivamente fechada, mesmo para os mais fanáticos dos homens, que a tolerância tem sua razão de ser, mas ela não é suficiente e supõe que a razão seja posta a seu serviço para fazê-la triunfar, ideia sobre a qual insiste Voltaire em seu Tratado sobre a tolerância com uma boa dose de otimismo: "O grande meio de diminuir o número de maníacos, se restarem, é submeter essa doença do espírito ao regime da razão, que esclarece lenta, mas infalivelmente, os homens. Essa razão é suave, humana, inspira a indulgência, abafa a discórdia, fortalece a virtude, torna agradável a obediência às leis, mais ainda do que a força é capaz" (VOLTAIRE, 1993, p. 33).

Porquanto no plano dos valores e da racionalidade é o combate intelectual que prevalece, a vontade que cada um tem de impor suas ideias, a tolerância não se imporia sem a luta conduzida por aqueles para quem ela é um valor fundamental. Nada proíbe buscar reconduzir à razão os entusiastas e os fanáticos e tentar demonstrar a eles a correção dos fundamentos da tolerância, o que Voltaire faz em longas páginas ao denunciar 
o absurdo dos dogmas que conduzem à intolerância, a contradição performativa dos cristãos que perseguem em nome de um Deus ele próprio perseguido ou que se valem de passagens da Escritura para justificar a intolerância, o caráter contra produtivo do constrangimento em matéria de fé e das perseguições no nível econômico e social, a impossibilidade real de atingir um acordo nesses domínios que ultrapassam os limites da razão, a desumanidade dos suplícios, a inversão dos valores que consiste em punir mais severamente uma conduta irreligiosa do que uma conduta imoral, o ridículo das controvérsias teológicas, tudo isso a fim de conduzir os entusiastas não somente a tolerar as outras seitas cristãs mas igualmente todas as opiniões contrárias às suas em nome de uma fraternidade universal que o capítulo XXII do Tratado sobre a tolerância valoriza: "Não é preciso uma grande arte, uma eloquência muito rebuscada, para provar que os cristãos devem tolerar-se uns aos outros. Vou mais longe: afirmo que é preciso considerar todos os homens como nossos irmãos. O quê! O turco, meu irmão? O chinês? O judeu? O siamês? Sim, certamente; porventura não somos todos filhos do mesmo Pai e criaturas do mesmo Deus?" (VOLTAIRE, 1993, p. 125). Esta tolerância universal fundada sobre um princípio de fraternidade vale logicamente para as opiniões dos próprios entusiastas, que devem ser tolerados na medida em que buscam apenas defender suas opiniões no terreno das ideias e a convencer pelo diálogo os seus interlocutores. As concessões feitas porVoltaire ao fanatismo e ao dogmatismo têm certamente seu limite natural, e repousam no fundo sobre uma distinção essencial que Voltaire apresenta no artigo "Fanatismo" do Dicionário Filosófico: "O fanatismo está para a superstição como o arrebatamento para a febre ou a raiva para a cólera. Aquele que experimenta êxtases, visões, que toma os sonhos por realidades e as suas imaginações por profecias, é um entusiasta; aquele que sustenta sua loucura pelo assassinato, é um fanático" (VOLTAIRE, 1968, p. 105). No momento em que essas opiniões se transformam em ações, em que o entusiasta se transforma em fanático, a tolerância deve dar lugar à repressão. O problema da tolerância religiosa se torna político.

\section{De Hobbes a Voltaire: a questão da tolerância política}


No que diz respeito à tolerância política ou civil, ela é pensada de partida sob a forma de uma alternativa: deve-se favorecer a ideia de uma religião de Estado ou pensar o Estado como o fundamento da coexistência de diversas religiões? No primeiro caso, a questão que se põe é a da compatibilidade entre a obediência a Deus e a submissão ao soberano, e esta questão conduz ao problema de saber se não haveria uma hipocrisia em praticar exteriormente um culto oficial que não corresponderia à fé interior dos indivíduos. Hobbes e Espinosa propuseram uma resposta idêntica a esse problema, que consiste em dissociar a fé interior e o culto oficial exterior imposto pelo soberano, e a submeter o religioso ao político. Em Hobbes, uma igreja é definida sob a forma de uma comunidade de crentes que é autorizada apenas pelo soberano, este último pode impor legitimamente um culto oficial a todos seus súditos enquanto chefe da Igreja, como lembra o capítulo 39 do Leviatã ${ }^{2}$. O que gera um problema nesse caso é a situação de um cristão que vive em um país que não é submetido a um soberano cristão. Para Hobbes, levado em conta aquilo que é necessário à salvação do ponto de vista religioso, isto é, a fé, um cristão submetido a um soberano não cristão deve reconhecer a soberania sob a qual ele vive e se submeter às leis promulgadas ou, em caso extremo, se a defesa de sua religião tem mais importância que sua vida, ele pode aceitar sofrer o martírio, mas aceitando o castigo previsto para a violação das leis como faziam os primeiros mártires cristãos sob o Império romano. Isso vale igualmente para os conflitos entre cultos ou artigos de fé que sejam contrários à lei natural, como o caso da aceitação do sacrifício humano nesta ou naquela cultura, ou contrários à lei civil, o caso da exaltação do assassinato, do suicídio ou da mentira, exemplos evocados por Locke e que não deixam de lembrar Antígona de Sófocles. É, certamente, possível desobedecer à lei civil em nome de princípios religiosos ou éticos, o critério de sinceridade prevalece sobre qualquer outra consideração neste caso, mas esta escolha feita com consciência naturalmente expõe aquele que a faz à pena ligada a esta desobediência.

É igualmente a tese que sustenta Espinosa no capítulo 16 do Tratado teológico-político, no qual ele mostra que o súdito político deve ao mesmo tempo ser submisso a Deus, mas também ao soberano legítimo, que tem perfeitamente o direito de estatuir em matéria de religião. O que acontece no caso de um cristão submetido a um soberano não cristão? Espinosa 
responde como Hobbes: ou bem ele recusa a obediência e aceita o castigo legítimo ligado a toda insubordinação, ou bem ele se submete e respeita as leis civis. Esta análise é reforçada pelo capítulo 19 do Tratado teológico-político no qual Espinosa insiste sobre a subordinação da religião ao Estado e ao soberano a partir de três teses essenciais: (1) a religião só adquire força de lei pelo soberano; (2) não há divisão entre o reino de Deus e o reino político; (3) cabe ao soberano legislar sobre o culto, o culto nada causa ao fervor interior dos indivíduos. Resta dizer que Espinosa se separa de Hobbes em um ponto essencial quando ele faz notar, no capítulo 20 do Tratado, que a conduta mais vantajosa para a república é a de favorecer a liberdade de pensar e a liberdade de expressão. $O$ que quer dizer que a força da república é compatível com a pluralidade de cultos e a tolerância de particularidades religiosas, como atesta a seu ver a situação excepcional da Amsterdã de seu tempo.

Consideremos a segunda alternativa, aquela para a qual uma pluralidade de cultos é possível no Estado sem que haja uma oposição entre um culto oficial e outros cultos. Os partidários desta liberdade de culto consideram que a liberdade de crença é fundamental para a sinceridade religiosa, a imposição de um culto oficial apenas encorajaria os comportamentos hipócritas. Isto é o que faz a originalidade da posição de Locke. Partindo de uma posição hobbesiana em 1660, em que predomina ainda a necessidade de imposição pelo soberano de um culto oficial, Locke vai mostrar depois, a partir do Ensaio sobre a tolerância, mas, sobretudo a partir da Carta sobre a tolerância, que o político não pode nada impor à consciência e que, portanto, todos os cultos devem ser autorizados. Esta evolução se explica pela necessidade de rever a distinção habitual entre as coisas necessárias à salvação e as coisas indiferentes à salvação. Para Locke, é necessário à salvação aquilo que a consciência crê essencial para ser salva, mesmo que ela se engane. O que quer dizer que não há mais coisas indiferentes à salvação. Da mesma maneira, existe um direito essencial à consciência errante, desde que a crença seja de boa fé e não hipócrita, e que as crenças reivindicadas pela consciência sejam verdadeiras ou falsas. Sendo assim, o reconhecimento desse direito religioso não deve impedir o reconhecimento dos direitos políticos. Em caso algum o reconhecimento dos direitos religiosos deve pôr em perigo a obediência civil e a ordem civil, o que implica que são excluídos da tolerância civil aqueles 
que não se submetem conscientemente à lei civil, a saber, os ateus e os católicos, que não podem ser sinceros - os ateus se submetem a ordem civil apenas de uma maneira exterior, já que recusam a submissão ao legislador soberano que é Deus; e os católicos são também hipócritas, pois, ainda que se submetam a Deus, contrariamente aos ateus, eles se submetem também ao papa e não ao soberano legítimo do Estado no qual vivem. Bayle pensa também que é preciso restringir a tolerância no que se refere aos católicos por causa do perigo político que eles representam, e não por razões religiosas. Mas, no que se refere aos ateus, Bayle reconhece nos Pensées diverses sur la comete a possibilidade do ateísmo virtuoso e a fortiori a de uma sociedade viável de ateus. Mesmo considerando a oposição entre Locke e Bayle, digamos que para estes dois partidários da pluralidade de cultos existe, no entanto, limites políticos à tolerância religiosa.

No quadro desse segundo debate,Voltaire parece ainda seguir seus predecessores. Como Hobbes, ele distingue de início aquilo que concerne à consciência individual (o direito de cada um crer naquilo que quer) e aquilo que concerne à ação pública (o direito de impedir toda sedição executada em nome de crenças religiosas), como lembra o artigo "Catecismo chinês" do Dicionário Filosófico: "A lei natural permite a cada um crer naquilo que quer, como de se alimentar do que quer. Um médico não tem o direito de matar seus doentes porque eles não observaram a dieta que ele lhes prescreveu. Um príncipe não tem o direito de mandar prender aqueles de seus súditos que não pensam como ele; mas ele tem o direito de impedir as agitações" (VOLTAIRE, 1968, p.127). A tolerância religiosa exige uma liberdade de consciência que não encontra limites a não ser políticos, quando a ordem pública é posta em questão. Nada é mais essencial do que evitar a anarquia, e o político deve tomar os meios que se impõem a ele para impedir tal transformação da ordem social.

Ainda como Hobbes, ele insiste na indispensável separação dos domínios religioso e político, ou melhor, a necessária submissão da religião ao político. Nenhuma atividade religiosa pode ser exercida sem o acordo do político, nenhum membro do clero pode estar isento do controle do magistrado no exercício de sua função, nenhum dogma pode ser promulgado sem ter recebido a sanção governamental.Voltaire é então partidário de uma religião submetida ao poder temporal, daí a distinção proposta entre a religião de Estado, que nada mais é do que uma religião civil cujos 
ministros de culto ocupam somente funções administrativas e educativas, e a religião teológica que alimenta a superstição e o fanatismo. Pouco importa se esta religião civil empresta seu ritual desta ou daquela religião revelada, o essencial é que aqueles que a pregam o façam de acordo com ordens claras editadas pelo magistrado e que limitem sua ação a tarefas precisas, a mais importante é lembrar a seus concidadãos o respeito devido a Deus e ao seu próximo. A partir disso, compreende-se porque Voltaire não valoriza, como fazia Locke, a coexistência de diversas religiões no seio de um Estado que colocaria os diferentes cultos em pé de igualdade, e porque ele aceita melhor, como Hobbes, a desigualdade de tratamento existente entre os partidários de um culto oficial e os sectários de religiões diferentes, notadamente no que se refere à atribuição de cargos públicos, como acontecia com os católicos na Inglaterra. Escolher não fazer parte da igreja nacional significa aceitar não poder se beneficiar das prebendas públicas, desigualdade de tratamento que é aceitável desde que os direitos civis de todos sejam respeitados, como indica Voltaire rapidamente no Tratado sobre a tolerância: "Não digo que todos que não são da religião do príncipe devam ter acesso aos postos e às honras dos que são da religião dominante. $\mathrm{Na}$ Inglaterra, os católicos, vistos como adeptos do partido do pretendente, não podem aspirar aos cargos; pagam inclusive imposto dobrado; mas, afora isso, gozam de todos os direitos dos cidadãos" (VOLTAIRE, 1993, 26).

Do mesmo modo, ainda como Hobbes e em nome da paz civil, Voltaire distingue o direito de consciência em questão religiosa do dever de obediência em matéria política. Todo cidadão tem a obrigação de se submeter ao soberano, partilhando ou não com este último suas crenças íntimas, e toda rebelião contra um soberano legítimo deve ser reprimida. A tolerância não pode ser reduzida à indiferença e o essencial é sempre a preservação da ordem social e, portanto, da liquidação do espírito de fanatismo. A esse respeito, de acordo com Voltaire, uma melhora se apresenta, e os progressos da razão, o recuo da superstição, a difusão das Luzes, as reformas jurídicas, o espírito do tempo, o impacto dos trabalhos dos philosophes, a multiplicação das seitas que respeitam as leis, são elementos que permitem pensar que a tolerância vai se generalizar e que os excessos do fanatismo só podem retroceder a curto prazo. Aí se reencontra o otimismo já evocado anteriormente e que outra passagem do Tratado sobre a 
tolerância lança luz: "A cada dia a razão penetra na França, tanto nas lojas dos comerciantes como nas mansões dos senhores. Cumpre, pois, cultivar os frutos dessa razão, tanto mais por ser impossível impedi-los de nascer. Não se pode governar a França, depois de ela ter sido esclarecida pelos Pascal, os Nicole, os Arnaud, os Bossuet, Os Descartes, os Gassendi, os Bayle, os Fontenelle, etc., como a governavam no tempo dos Garasse e dos Menot" (VOLTAIRE, 1993, p. 119-120).

Resta saber se limites devem ser impostos a esta tolerância geral, notadamente no que concerne ao problema espinhoso dos ateus colocado por Bayle. A esse respeito, Voltaire elabora uma solução audaciosa que se distancia ao mesmo tempo da tese de Locke, para quem uma sociedade de ateus é impossível, e daquela de Bayle, para quem um agrupamento de ateus é não somente possível mais igualmente não prejudicial ao funcionamento do Estado. Que uma sociedade de ateus seja possível é, para Voltaire, evidente e a história, mais do que a geografia, já mostrou isso. Com efeito, ao invés de citar exemplos sobre esta questão se referindo a populações distantes, Bayle deveria ter pensado nas sociedades filosóficas da Antiguidade, e em particular nos epicuristas e, ainda melhor, citar o senado romano do tempo de César e Cícero.

O interesse deste exemplo histórico é que ele permite julgar a viabilidade do ateísmo político. Mesmo que não lhe reste dúvida de que o ateísmo é preferível ao fanatismo, não deixa de ser possível que ele conduza à dissolução do político, como a queda da república romana provou. No fundo, o ateísmo virtuoso, salvo exceção raríssima, é uma contradição em termos, pois sem o reconhecimento de um Ser superior remunerador e vingador nenhum freio é colocado às paixões dos homens, e são a elas que se deve a destruição da ordem civil. Se Voltaire une-se a Locke no final, pensando que, "em uma cidade policiada, é infinitamente mais útil haver uma religião, mesmo ruim, que não haver nenhuma” (VOLTAIRE, 1968, p.388), e "que a santidade dos juramentos é necessária" (VOLTAIRE, 1968, p.388), não é como este último em nome de exigência teóricas, mas a partir do exame de um caso concreto, o da república romana, que lhe parece poder servir de lei geral.

Apesar de tudo, é melhor viver num Estado em que predomine uma religião, mesmo ruim e capaz a qualquer momento de se deixar submergir pelos excessos de fanatismo, do que viver em uma sociedade de ateus 
na qual é por definição impossível de se fiar a quem quer que seja. A melhor solução seria sem dúvida viver num Estado em que tudo é feito para que a religião civil não se transforme em religião teológica. A questão que se impõe agora é saber como chegar a isso, quer dizer, como chegar a vencer a superstição, que conduz ao fanatismo, sem que o combate não recaia sobre o governo que o realizou. Questão difícil, como reconhece Voltaire: "é perguntar a que ponto se deve fazer a punção de um hidrópico, que pode morrer na operação. Isso depende da prudência do médico" (VOLTAIRE, 1968, p. 543-544). Médico do corpo social,cabe ao político saber conjugar tolerância e repressão a fim de cumprir sua função, que é a de permitir a convivência e de favorecer o bem comum.

Mesmo que Voltaire não tenha proposto a seus leitores uma reflexão teórica sistemática sobre a tolerância, como fizeram Locke e Bayle, sua abordagem não deixa de ser profundamente original. Com efeito,Voltaire não se contentou em retomar as problemáticas de seus predecessores, ele reconsiderou-as profundamente a partir de sua própria filosofia, com o intuito de integrá-las em um plano mais amplo no qual adquirem uma nova dimensão. Esta dimensão é a do teísmo metafísico indissociável de uma concepção nova da política, separada de toda sujeição teológica e preocupada tanto com a liberdade de pensamento e de expressão de cada um quanto com os limites a serem impostos às ações inspiradas por esta liberdade, certamente indispensável, mas não total. De todos os pensadores das Luzes, parece ser ele quem mais antecipa as reflexões de John Stuart Mill sobre esta mesma questão e, portanto, sobre as nossas hoje.

\footnotetext{
${ }^{1}$ Jacques Acontius, Les ruses de Satan recueillies et huit livres, Bâle, Peter Perne, 1565.

${ }^{2}$ Hobbes, Leviatã, São Paulo, Col. Os Pensadores, Abril Cultural, 1974, cap. XXXIX, p. 281: «(...) defino uma Igreja como uma companhia de pessoas que professam a religião cristã, unidas na pessoa de um soberano, a cuja ordem devem reunir-se, e sem cuja autorização não devem reunir-se."
}

\section{Referências bibliográficas}

BODIN, J. 1984. Colloque entre sept savants qui sont de différents sentiments, Genève: Droz. 
CHERBURY, E. 2002. Le salut du laïc, Paris:Vrin.

HOBBES. 1971. Léviathan, Paris: Sirey.

LECLER, J. 1994. Histoire de la tolérance au siècle de la réforme, Paris: Albin Michel.

LESSING, 2006. Nathan le sage, Paris: Gallimard, acte III, scène 7.

VOLTAIRE, 1968. CEuvres complètes, éd.Voltaire Foundation, Oxford:

Oxford University Press.

VOLTAIRE, 1993. Tratado sobre a tolerância. Trad. Paulo Neves. São Paulo: Martins Fontes. 